Engagement with meditation as a positive health trajectory: Divergent narratives of progress in male meditators 
Objective: Studying personal narratives can generate understanding of how people experience physical and mental illness. However, few studies have explored narratives of engagement in health positive behaviours, with none focusing on men specifically. Thus, we sought to examine men's experiences of their efforts to engage in and maintain healthy behaviours, focusing on meditation as an example of such behaviour. Design: We recruited 30 male meditators, using principles of maximum variation sampling, and conducted two in-depth interviews with each, separated by a year. Main outcome measures: We sought to elicit men's narratives of their experiences of trying to maintain a meditation practice. Results: We identified an overall theme of a 'positive health trajectory,' in particular, making 'progress' through meditation. Under this were six main accounts. Only two articulated a 'positive' message about progress: climbing a hierarchy of practitioners, and progress catalysed in other areas of life. The other four reflected the difficulties around progress: progress being undermined by illness; disappointment with progress; progress ‘forgotten’ (superseded by other concerns); and progress re-conceptualised due to other priorities. Conclusion: Men’s narratives reveal the way they experience and construct their engagement with meditation as an example of health behaviour - in terms of progress.

Key words: health and well-being, health behaviour, masculinity, meditation, men's health, mental health 


\section{Gender and health}

A considerable body of literature has emerged exploring gender differences in health and health behaviour. The current life expectancy of men in the United Kingdom is 4.1 years lower than women (Office for National Statistics, 2012), and men have higher mortality and morbidity rates on most heath indices (Courtenay, 2000a). In accounting for these trends, theorists suggest men are influenced by dominant cultural norms which can be problematic, and that such health differentials are a result of men enacting masculinity (Courtenay, 2000b). For instance, risk-taking - a prominent way for men to perform masculinity accounts for much of the 'male mortality excess' (among 15-29 year-olds, male deaths outweigh female ones by 2.6 to 1) (Phillips, 2006). Masculinity is also linked to mortality/morbidity through poorer health behaviours. For example, men are commonly constructed as reluctant to seek help, attributed in part to norms that discourage men from admitting vulnerability (Addis \& Mahalik, 2003). Together, these kind of findings have generated a prominent discourse in the literature, and society at large, which portrays men in singular terms as ‘damaged and damage doing’ (Mac an Ghaill \& Haywood, 2012, p.483), positioning masculinity as a 'risk factor' for health (Gough, 2006).

However, theorizing in gender has led to recognition of variability within and across men (Connell, 1995). Thus, scholars have recently sought to refine our understanding of the intersection between masculinity and health, developing more nuanced conceptions of the potential for men to act in health-promoting ways, moving away from simple gendered binaries (e.g., that men ‘do’ health badly, and women ‘do’ it well) (Sloan, Gough, \& Conner, 2009). Recent studies have shown that men are able to act in ways that are considered health promoting, although men may still engage in discursive work to justify these behaviours in the context of masculinity. For example, help-seeking for medical concerns - often seen as contrary to the prescription that men be tough and autonomous - was justified by some men 
as a wise use of healthcare services, in contrast to the less-informed behaviour of 'weaker' men (Noone \& Stephens, 2008). Likewise, while alcohol use is a way for men to demonstrate masculinity, some men justified abstinence by positioning it as a manifestation of other masculine norms such as independence from the herd (de Visser, Smith, \& McDonnell, 2009). Similarly, Sloan et al. (2010) studied men who engaged in regular exercise, and found they eschewed speaking directly about health - presenting health concerns as feminine - but justified their behaviour by invoking traditionally masculine discourses of action, success, and autonomy.

\section{Health behaviours}

These studies paint a more nuanced picture of the potential for men to act in ways conducive to health, even if they reveal complexities in how men account for such actions. However, there is little detailed analysis of men's attempts to engage proactively in health behaviours over an extended period of time, and the challenges involved in so doing. Health behaviours can be defined as: ‘Any activity undertaken by an individual, regardless of actual or perceived health status, for the purpose of promoting, protecting or maintaining health' (Nutbeam, 1998, p.355). Assessment of what constitutes health behaviours depends upon one's definition of health. Larson (1999) suggests health is a contested concept, used in diverse ways, with at least four different models in common usage. The 'medical model' identifies health (physical and mental) as the 'absence of disease and disability' (p.124). A more 'holistic' model is provided by the 'World Health Organization' (1948), with an inclusive definition of health as 'a state of complete physical, mental and social well-being, and not merely the absence of disease and infirmity.' Similarly, advocates of the 'wellness' model are concerned with ‘progress towards higher levels of functioning’ (Larson, 1999, p.129), not with simply 'fixing dysfunction.' The wellness model is more esoteric in that it incorporates ‘spiritual’ wellbeing in its assessment of health; e.g., Neilson (1988, p.4) 
emphasises the 'integration of the total individual - body, mind, and spirit - in the functioning process.' Finally, the environmental model conceptualises health as successful adaptation to one’s environment.

These diverse conceptualisations of health offer considerable latitude in terms of what is deemed a 'health behaviour.' In the narrowest sense, health behaviours are activities linked to reduced physical morbidity and mortality, e.g., regular exercise and a healthy diet (Conner \& Norman, 1998). Yet even in the medical model - the most restrictive of Larson's models health is not identified exclusively with physical functioning, but also includes mental health. On this broader reading, any activity that reduces ‘mental disease and disability’ counts as health behaviour. More expansively, according to the World Health Organization and wellness models, health behaviours are any activities that promote physical, mental, or social wellbeing. Like health, wellbeing itself is a contested term (de Chavez, Backett-Milburn, Parry, \& Platt, 2005). However, influenced by the World Health Organization model, the emergent 'positive psychology' movement has defined wellbeing as not simply absence of mental illness, but as ‘flourishing’ (Ryff, 1989). Here wellbeing is operationalized through such constructs as 'psychological wellbeing,' which concerns 'optimal functioning,' including personal growth. From this more encompassing perspective, health behaviours are activities which improve any dimension of wellbeing, e.g., personal growth. Thus, a broad working definition of health behaviours, encompassing the four models above, is: activities which (a) promote physical health, and/or (b) alleviate mental illness/distress, and/or (c) promote wellbeing (including psychological, social, and even spiritual dimensions).

\section{Meditation and health}

An example of an activity which potentially incorporates all three 'aspects' of health behaviour is meditation. Meditation is 'a family of self-regulation practices that focus on training attention and awareness in order to bring mental processes under greater voluntary 
control and thereby foster general mental well-being' (Walsh \& Shapiro, 2006, p.228-229). Firstly, meditation has been shown to reduce health-risk behaviours, e.g., alcohol use, and has been adapted as a clinical treatment for addiction disorders (Witkiewitz, Marlatt, \& Walker, 2005). Meditation is also associated with health behaviours like exercise maintenance (Ulmer, Stetson, \& Salmon, 2010) and improved diet (Dalen et al., 2010). Analysis of biological changes associated with meditation suggest it may enhance immune system functioning (Davidson et al., 2003). As a ‘distress-reducing’ behaviour, meditation can reduce levels of depression and anxiety in clinical and non-clinical populations (Mars \& Abbey, 2010). As such, meditation has been adapted as a clinical intervention for anxiety and depression (Teasdale et al., 2000), and has been recommended by the National Institute of Clinical Excellence (2004) as a treatment for recurrent depression. Finally, as a 'wellbeingpromoting' behaviour, meditation produces improvements on indices of psychological wellbeing (Lee \& Bang, 2010).

However, despite widespread interest in meditation, little is known about how people engage with it in the context of their everyday lives. Most meditation studies are based on controlled interventions of limited duration, and usually fail to assess home practice outside of formal sessions (Vettese, Toneatto, Stea, Nguyen, \& Wang, 2009). When issues around practice maintenance are noted, they are generally only recorded as a methodological limitation. An exception is Williams, Dixon, McCorkle, and Van Ness (2011), whose 'Determinants of Meditation Practice Inventory’ assesses factors linked to poor attrition rates for meditation. However, this inventory was mainly based on research with expert panellists, rather than actual meditators. Thus, there is a lack of understanding about the way in which people practice meditation in the context of everyday life, with no research focusing specifically on men. 
The studies mentioned above show some men are acting in ways conducive to health, thus challenging the idea of masculinity as a 'risk factor' for health. Yet despite this emergent

strand of more 'hopeful' literature, men's engagement in health behaviours is a poorlyunderstood area. Most studies with positive messages on masculinity and health limit their assessment of engagement with health to a willingness to seek help, or to refraining from health-risk behaviours like alcohol use. How men pro-actively engage with health in a broader sense thus ends up being neglected. As such, we were particularly interested in two questions: can meditation function as a positive health behaviour for men? If so, how do participants experience and construct their engagement with this behaviour over time?

\section{Methods}

\section{Overview}

Thirty male meditators were recruited in London, United Kingdom, using principles of maximum variation sampling (Marshall, 1996). We elicited narratives around experiences of meditation via two semi-structured interviews (separated by at least a year in 2009 and 2010).

\section{Participants}

Inclusion criteria included that participants be older than 18 and were practicing meditation, though not as part of a clinical intervention. Recruitment was mainly through one meditation centre, plus other events attended by meditators in London. A purposive maximum variation sampling strategy was used (Marshall, 1996), aiming to include the widest practical range of socio-demographic backgrounds. Sampling occurred concurrently with, and was influenced by, the emerging data analysis, which suggested the inclusion of certain men to clarify the emerging analysis, thus increasing its robustness and credibility (Cutcliffe, 2005). For example, men were sought who were unaffiliated with a meditation group to contrast experiences with men who had access to a group. A diverse sample of participants was obtained as outlined in Table 1; all lived and/or worked in London. 
[Insert table 1 about here]

\section{Data collection}

Interviews were semi-structured, and undertaken by the first author at a location selected by the participants (their homes or places of work, the meditation centre, or the university). On average, the first interview (Time 1; T1) lasted around two hours, and the follow-up interview (Time 2; T2) around an hour. Before the T1 interview, participants signed an informed consent form and completed a demographic survey. The project was approved by the University Research Ethics sub-Committee, and an ethics protocol was in place to ensure participants' wellbeing. The interview approach was designed to be sensitive to men, providing a safe space for them to tell their own story in their own words. Separate interview guides for T1 and T2 were devised in consultation with the literature and the research team.

Interviews were designed to elicit men's narratives of their engagement with meditation over time. While narratives are a contested concept, there is consensus that, in an elemental sense, they are stories about experiences, offering a useful 'means of understanding experience as lived and told’ (Savin-Baden \& Niekerk, 2007, p.259). This 'lived-told’ distinction broadly reflects Ricoeur's (1981) differentiation between a hermeneutics of 'faith' and of 'suspicion.' The former involves an 'empathic-interpretative' perspective in which we 'trust' respondents' account to reveal historical details about their experiences. The latter recognizes the performative functions of narrative as people construct self-identities through discourse. Together, the two perspectives provide a 'more complete understanding of the participant’s lived experience’ (Frost et al., 2010, p.15). As Smith and Sparkes (2005) show, narratives offer important analytical clues about men's experiences of health and wellbeing.

T1 interviews elicited narratives leading up to engagement with meditation, and up to the present. Following a set opening invitation ('Tell me a bit about life before meditation.'), the interview guide contained prompts to elicit narratives of particular experiences if not 
mentioned spontaneously by participants (e.g., 'Tell me about the first time you tried meditation.'). The T2 interview sought to elicit narratives concerning the intervening year, using an opening invitation ('Tell me a bit about how this year has been.'). The two opening invitations were designed to be sufficiently open-ended to allow men to begin their narrative at the point - and in the way - they felt to be most important. We encouraged the inclusion of any aspect of life experience men felt to be relevant. Interjections were used to draw out the narratives (e.g., 'Then what happened?'). At both interviews, after men had finished their story, particular topics of interest were followed up, i.e., returning to episodes in the narrative that warranted revisiting for more detail, and inquiring about topics (if not already covered) such as health and wellbeing.

\section{Data analysis}

Interviews were professionally transcribed. To ensure anonymity, details likely to lead to identification were removed. Transcripts were emailed to participants for approval, which all participants granted. NVivo software was used to help organize and analyse the data. This article focuses on the T2 transcripts, featuring narratives of the intervening year (two previous articles focused on the T1 data, one examining narratives of the reasons men began meditating (Author et al., XXXXa), and one investigating the development of awareness through meditation (Author et al., XXXXb)). It was considered that focusing on a limited time-frame of one year would enable assessment of issues around attempts to maintain a practice. The data analysis was influenced by a 'modified' constant comparison approach (Strauss \& Corbin, 1998). This follows the initial stages of modified grounded theory, and likewise involves linking with literature to clarify the emerging analysis (Cutcliffe, 2005). However, modified constant comparison stops short of developing a theoretical framework, aiming to articulate relations between key themes. The first analytic stage was open-coding. Each transcript was read through paragraph-by-paragraph, with emergent themes noted. The 
next stage involved grouping themes together under higher headings according to conceptual similarity. Each transcript was organised under one categorical heading encapsulating the 'gist’ of narrative, reflecting events depicted within. For example, one man’s year was dominated by a serious illness, generating the heading 'practice undermined by illness.' To avoid confusion, since we did not conduct a narrative analysis, but rather analysed men's narratives using modified constant comparison, these categorical headings will be referred to as 'accounts' rather than 'narratives.'

Once each transcript had been summarized in this way, the headings of all transcripts were compared, looking for common themes. The headings were then grouped into larger overarching 'account' headings according to conceptual similarity. For example, the 'practice undermined by illness' account was grouped with similar accounts to produce an overarching account named ‘torn apart.’ In total, six overarching accounts were identified, each reflecting a common set of experiences shared by a number of men. Finally, the six accounts were all grouped under an overarching theme of 'progress.' The analysis was aided by quality-checks to enhance validity (Strauss \& Corbin, 1998). For example, 'negative case analysis’ involves searching for counter-examples to emergent themes, enabling nuances to be identified within the overarching progress theme. The analysis was further strengthened by triangulation - the ‘combination of methodologies in the study of the same phenomenon’ (Denzin, 1978, p.291) - specifically investigator triangulation, since on-going consultation with the research team over a number of years helped to develop the codes and refine the analysis.

\section{Results}

T2 interviews yielded narratives focusing mainly on experiences of the previous year (from T1 to T2). Although each man had unique experiences over the 12 months, there were six main types of story. All stories centred on a meta-theme of making some kind of 'progress' through meditation (apart from one account - 'stepping off' - which as such is the exception 
that proves the rule). Men conceptualised the notion of progress in different ways, drawing on ideas around spirituality, health and wellbeing. These ideas often intertwined in interesting ways. For example, one man spoke about making 'spiritual' progress, but then defined this as becoming 'a healthier, happier human being.' Other goals included: becoming 'integrated,' closer to God, better at meditation, refraining from alcohol, getting 'ordained,' being less depressed, or finding more self-confidence. However, across all the different ideals of progress, there were six main accounts, each describing different types of success and failure.

- 'Climbing': Progress was made, e.g., along a spiritual path.

- 'Springboard': Progress was catalysed in other areas of life.

- 'Getting bogged-down’: Progress was stalled.

- 'Torn apart': Progress was disrupted by serious problems.

- 'Stepping off': Progress was replaced by other priorities.

- 'The reckoning': Progress was re-conceptualised due to existential concerns.

These six accounts are explored in turn below, illustrated with interview excerpts in italics. The number of men articulating each account was reasonably evenly spread across the six categories. All names used are pseudonyms.

\section{'Climbing'}

In discussing the year from $\mathrm{T} 1$ to $\mathrm{T} 2$, some men articulated an account of their meditation practice flourishing. Here, flourishing generally meant making progress along a 'spiritual path' that informed their practice. In particular, since many participants were attached to a specific Buddhist movement, this involved following a model of progression outlined by the movement. This progression centred on seeking 'ordination,' which produced the impression of men 'climbing' up a hierarchy of practitioners within the movement. At T1 interviews, most participants in the study produced a general narrative of progress stretching back to their initial involvement with meditation. These earlier progress narratives had often been about 
overcoming issues, such as mental health problems, particularly anxiety and depression. With this 'climbing' account at T2, a number of men continued this 'progress' narrative, but articulated it in more positive terms, e.g., moving towards positive health generally (' $a$ healthier, happier human being.'), and ordination specifically. Moreover, each man appeared to be at different 'stages' of their meditation 'career.' Thus, their stories seemed like steps on a common path. First, as a relative newcomer, Buddhism was 'shifting to become the central focus' of Dean's life. He had begun helping at the Centre, and having waited four years to undertake a solitary retreat, was pleased to have successfully completed his first one. His account of spiritual progress focused mainly on emotional health: 'Amazing. [I've had] a boost to my emotional self-sufficiency.'

Having lived in the centre for a few years, Steven felt he had gained a specific identity, and that life now had direction ('I was all over the place before. Now I'm 'Steven the Buddhist."'). His account was complicated in that he had recently moved out of the centre to live with his girlfriend, despite enthusing about living there at T1 - the 'final straw' was her inability to visit when he was ill, due to the centre enforcing a single-sex policy in the accommodation quarters. However, he was very committed to Buddhism, and had just asked for ordination, i.e., public recognition of his commitment to Buddhism by the movement to which that centre was affiliated. This emphasis on communal recognition is indicative of the multidimensional nature of progress, in this case highlighting its social dimensions: 'My life plan is to do the ordination process . . . because it's the most meaningful thing I've found to do with my life.'

At the next stage was Dalton: After working toward ordination for five years, his 'big news' was that he had been approved. He articulated an 'interesting mix' of excitement and 'nervousness,' which he felt was appropriate since ordination meant 'making a commitment for the rest of your life': 'It feels like fear ... of stepping into the unknown. It's kind of the 
right response, because ... I don't know who I'm going to be.' While Strauss et al.'s (1984) work on illness trajectories shows identity work occurs in relation to illness, the above excerpts show that identity work also occurs in relation to positive health activities.

Despite expressing disenchantment with the meditation centre at T1 (because of an unpleasant personal conflict), Grant had still sought ordination. He had just returned from the four-month ordination retreat ('Fascinating, challenging, beautiful.'). He was adjusting to his new identity, including a new Buddhist name ('It recognizes my better qualities. I'm very pleased.'), which again highlights the process of identity work undertaken by men here. He also reflected on the accessories to progress: How people’s perceptions of him would likely be different now ('They expect certain standards of behaviour. We've been warned.'). He was trying to be careful about gaining 'respect which is not necessarily earned,' worrying about how he appeared, e.g., resisting 'status symbols,' like a shaved head: 'Friends would get a false message that I've sort of made some great discovery, [which] didn't feel right.'

Finally, some who had been ordained for some years felt they had taken progress to new levels. Jack had been trying to cultivate 'more of a reverential element' to his practice, and felt he had recently found an elevated sense of spirituality, including opening up to the possibility of God 'There's a big mystery out there. .. Y You can get a hell of a long way on the spiritual path believing in a God. . . . That's some of the stuff I've been working on.'

\section{Springboard}

Other men were also happy with their practice, but their accounts focused on how it had enabled them to do other things. Being content with their initial progress in meditation, they felt it had enabled them to make unanticipated progress in other areas of life. They had turned to meditation after a crisis (e.g., a breakdown), and were still relative novices. They described acquiring confidence to flourish elsewhere in life; their stories were full of optimism and joy. 
Since suffering depression a few years ago, Terry had been recovering through therapy and the 'support' of the Centre. However, he had just ended his therapy since it had 'done [its] work' in terms of identity ('I got what I needed, [i.e.,] a good sense of who I am.'). He felt ready to 'move on,' and wanted to 'smash through' his 'imaginary cage' of limitations, and stretch himself. Although meditation had been, and still was, important to him, it was no longer central to his story. He had initially meditated to stave off depression ('To keep the wolf from the door.'); now he felt strong enough to not meditate daily. He himself suggested he had found a new narrative around meditation ('I'm able to be a bit freer with my story about meditation.'). Ali was similar: Although still committed to meditation which helped him feel more 'anchored and confident' - his story focused almost entirely on other 'challenges' he had set himself. His trajectory was veering off in unexpected directions, notably, an adventurous expedition.

Every time I think about it I feel overjoyed because ... I've got a goal. I see myself [at my goal], punching the air. It's just a great feeling, doing something outside my comfort zone. ... I'm taking an adventurous approach to life.

A different kind of catalyst account was articulated by experienced practitioners who had been ordained for years. Although meditation was still a major part of life, it had become the springboard for other spiritual activities which now mattered more. Sam's motivations for meditating had evolved over the years. Looking back, he felt his practice had previously been quite self-absorbed ('All about me, me, me.'). Having just reached an age milestone, he was in a reflective mood ('A mid-life crisis ... a strange age.'), and was starting to feel his personal progress mattered less to him now. He described a 'transition' where meditation had become a platform for a new focus on encouraging others, which was of greater value. As part of this, he had returned to his home city, and was establishing a new Centre there. 
It's time to use [my] experiences to give something back. ... This whole project is far more significant than just me meditating. ... I can't motivate myself anymore just because it makes me feel good. . . The way I am inspired now is through other people.

\section{'Getting bogged-down'}

In contrast to the first two accounts, other men betrayed a sense of unhappiness that, for all their efforts to engage in practice, they were not progressing as anticipated. These men still saw engagement with meditation in terms of a progress trajectory; however, they felt they were failing to advance along it. There were two stories here. Some were frustrated at life obstructing practice. Others were disappointed that their engagement was not as rewarding as they had hoped.

In terms of frustration, some men focused their narratives on how other aspects of life were crowding their practice. Showing how men felt they could fall behind in their progress, Kris felt that work and relationship demands had prevented him from progressing as he would have liked ('I've got a lot of catching up to do. . . I got distracted doing things I didn't want to.'). Similarly, Silas’s career had become increasingly stressful, affecting his ability to practice. Unlike the 'stepping off' account (see below), where men seemed less aggrieved that progress had been compromised by life demands, these men were frustrated by events, and had made efforts to address this. Kris had applied to a full-time meditation course ('Then perhaps I can go on to have a family, and feel I'm in a head-space where momentum will carry me.'). Silas had requested a less demanding work role: 'I'm trying to balance two lives. I know which is most important: my spiritual life. . . I'm going to do what gives my worldly life most meaning.'

Silas felt a full-time Buddhism 'career' (e.g., living/working in the meditation centre) would be 'very desirable.' However, some men with such a career narrated discontentment with their lack of progress, despite the opportunities afforded to them by their choices. 
Despite opportunities 'to practice more intensively,' Peter was 'disappointed' a long solitary retreat away from the 'distraction' of city life had not enabled him to go 'deeper' in meditation. Others found greater engagement in Buddhist-related activities, like volunteering at the Centre, dispiriting. For example, Adam called it 'boring.' It had been 'a challenging time' for him, and he had 'seriously thought about leaving [his Buddhist community]... I can live with it for a bit. ... I'm committed to being round here for a couple of years. I think by then I'll really have had enough.'

\section{'Torn apart'}

A small number of men articulated a version of the 'bogged-down' account that was so eventful that their trajectory had been totally disrupted. These men depicted a torrid time, involving serious physical or mental health issues which had a twofold impact: they stopped men meditating; and they interrupted men’s sense of progress.

These participants’ problems were so severe they reported being unable to meditate. Alvin experienced a psychotic episode - which he linked to heavy drug use after a break-up that led to him being hospitalized for two months ('To lose your mind, absolutely terrifying . . . scariest experience of my life.'), with a further five months recovering ('Reluctant to leave the house, confidence levels very low.'). Walter's life had 'unravelled' with an 'incredibly acute depression' lasting six months, described as an 'oppressive' darkness ('Deep apathy and bleakness ... stuck with these inner demons.'). William experienced a physical illness which was debilitating, physically ('Couldn't get out of bed, couldn't do anything for myself.') and emotionally ('A lot of suffering. My identity was pulled to bits.'). Of particular relevance here was that meditation was unable to help men during these times, and could even exacerbate problems (William: 'I just realized how much discomfort there is in my body.'). Moreover, these experiences undermined the broader changes men had been trying to make in their lives as a result of their engagement with meditation. William: 'Instead of being 
kind and generous and communicative and all those things I like to be, I went the other way, became worse, aggressive, distanced myself from the group.'

By the time of the interview, these men had tentatively resumed meditating. However, the temporary failure and cessation of their practice was thought to have undercut their progress. These men had felt they were changing for the better because of their engagement with meditation. This view had been shaken: the 'new self' they had been working on seemed to regress, and their 'old self' resurfaced (William: 'The bits I liked weren't there, and the bits I didn't like were coming to the surface. I found it very unsettling and painful.'). There were different responses to this disruption. William was dispirited by his 'regression,' and was struggling to reconnect with meditation, and with a broader commitment to Buddhism that had emerged out of his engagement with meditation.

I've not just questioned meditation, I've questioned whether I'm that committed to

Buddhism, and there's still that dialogue going on. Having had my practice fall to bits ... I can't quite be bothered to put everything back together.

In contrast, Walter framed his experience of depression positively. He presented a 'benefit-finding’ narrative of disruption, constructing it post-hoc as a learning experience, puncturing what he now regarded as hubristic over-confidence, which was counterproductive to progress ('I thought I was impervious to circumstance. Arrogance is a downfall to spiritual practice.'). Thus although disruptive, he argued that depression had paradoxically helped his 'progress.' Unlike William, his experience had reaffirmed the importance of meditation: 'It's a very important setback. . . brings to you the value of what you do. . . . Rather than it being a stumbling block, it’s more a really good lesson. .. . so humbling [and] eye-opening.'

\section{'Stepping off'}

For some men, a focus on meditation practice was largely absent from their narrative, or featured only peripherally. Here, progress was conspicuous by its absence, as if the men had 
'stepped off' the path or trajectory that characterised other participants' accounts. This differs from the 'bogged-down' and 'torn apart' accounts because these men appeared less concerned about their practice falling away. Many still meditated sometimes. However, progress had been overtaken by other concerns, as other dimensions of life assumed greater importance. Men were occupied by various issues. Ernest had been wrestling with a 'demanding' university course and the death of a family member ('A father figure to me.'), and caring for a 'suicidal' relative 'every weekend.' Colin had become a father, and despite exhaustion and worries ('I fear for her'), focused on how rewarding he found it ('I love being Dad'). Although these men mostly still tried to meditate, they had other priorities. Andrew had been taking a course that did not leave much time for meditation, or meeting other meditators: 'I've just been fairly pre-occupied [and] one-dimensional, just studying and working. [Meditating] in fits and starts, bumbling along.'

For these men, meditation had greatly subsided or stopped. Interestingly, they all still saw themselves as meditators, and continued to use discourses connected to meditation. For example, while Henry had grown weary of formal practice ('Another thing to do on top of everything else.'), he had recently become keen on swimming, which he found meditative ('It's just about being in the water.'). Likewise, Ernest experienced states of absorption similar to meditation though dancing. Despite little formal meditation ('Much less than it used to be.'), he went into 'meditative states all over the place. . . I'll sit at the station, look at a puddle, focus on the swirls, just breathe and find myself going down, relaxing.' These men gave the impression of not so much progressing in meditation as 'tapping into' it.

Thus, it was hard to say anyone had truly ceased meditation. Moreover, some suggested that commitment levels had been fluid: engagement waned, before resuming as motivation returned, with a sense of perhaps tentatively stepping back on to their progress trajectory. For example, Jimmy had been living in a meditation Centre, but this had been 
difficult ('As human beings it didn’t work.'). Moreover, he had also been convinced he was 'missing out' on the hedonism his old friends were still engaging in, and trying to 'tempt' him back to ('I had these fantasies about, "I'll go out drinking.”'). Jimmy, like many other men, had been encouraged to reduce alcohol consumption as a result of engaging with meditation. Some felt that drinking had a detrimental impact on their meditation practice. Others were influenced by Buddhist prescriptions around abstinence. However, like many, Jimmy found abstinence challenging. He 'rebelled,' stopped meditating, moved out, and returned to old patterns of drinking and using drugs. However, he had recently begun re-engaging with meditation, but from more of a distance, which he felt worked better.

I got on with living my life, but then thought, 'This isn't that great. I miss meditating, I should go back.' [Now] I feel much more connected, paradoxically, [though] literally I'm further away, but I think I work better outside a hothouse environment.

\section{'The reckoning'}

Like men who articulated the 'bogged-down' account, others also recounted difficult events during the year. However, for these men, the importance of these experiences was not that they had curtailed meditation practice, but they had forced men to confront their mortality in the face of their strivings for progress. These powerful existential reckonings had changed the way these men thought about meditation, and what progress meant in the light of one's eventual death. These men were essentially navigating a collision between a progress trajectory and the finiteness of mortality. Harry’s year was dominated by an illness ('Wallowing around in high anxiety around the fact I might suddenly [die].'), and caring for someone very close who had subsequently died ('Deep grieving. . . . I learnt the meaning of weeping.'). Dustin described trying to come to terms with ageing. He discussed the painful feeling that, having found meditation late in life ('A bloody long time to find my path.'), and finally gained a sense of wellbeing that had eluded him for years, he had little time left to 
reap the rewards. His story spoke of the sorrow of inevitable decline: 'The sad thing [is], time is against you. ... When you get the wisdom, your body decays in front of your very eyes. ... It feels like shit.'

These men still valued meditation, but its place in their lives was contextualized by their existential concerns. They dwelt on the spiritual significance of their progress, which consisted now in becoming better able to face death. Although Harry was concerned with 'the how' of dying ('I don't want to be in a lot of pain.'), he described trying to achieve 'greater acceptance' of the fact of it (however, invoking Buddhist ideas around reincarnation, he did leave open the possibility of continued existence after death). Having initially only meditated to cope with stress, he now saw his practice as being about negotiating death: 'I'm not afraid of death. If I go back to being a Buddhist, Buddhism's very much about preparing for death.'

Finally, although most men did not discuss having to contend with issues of mortality, many reflected in existential terms on their life, engaging with questions like, what was the point of their life? As Sam said, 'I have to make sure that I grow old and approach death and be able to say, “'I’ve done my best.”' Reflecting on these issues, most seemed glad to have made meditation part of their life. Even William, who was the most disillusioned, described wanting to 'reconnect' with meditation. Ross summed up this feeling that, on balance, for all the challenges around meditation, the journey was worth taking. He alluded to the film 'The Matrix,' in which, by picking a red pill over a blue pill, the protagonist chooses a painful but true reality over ignorant security. Although it had been a hard path, Ross had no regrets. It's like there's no way back, for better or worse. What a trip! Nobody told us before we embarked on this! . . . There were moments in my life, I've said, 'Shit, I should've taken the blue pill,' but deep down, absolutely no hesitation, I would take it again.

\section{Discussion}


Our article sheds light - for the first time in a detailed way - on men's attempts to engage in positive health behaviours, in this case, meditation. We were guided by two key questions: whether meditation could be construed as a health behaviour, and if so, how do men experience and construct their engagement in this behaviour? Based on our review of the literature, men's responses indicated that meditation could be constructed as a health behaviour. However, of particular conceptual importance was the answer to the second question. We found that men themselves constructed their behaviours in this area largely in terms of being on some kind of trajectory, and specifically as 'progressing'. (The conceptual import of this finding lies in the possibility that such experiences of a trajectory might apply to health behaviours generally, not just meditation specifically.) With reference to the notion of an 'illness trajectory' (Strauss et al., 1984), we might conceptualise the progress discussed by our participants as a 'health trajectory.' However, as explored below, this trajectory could be disrupted (e.g., by illness), transformed or undercut in various ways that made progress uncertain or otherwise problematic. Nevertheless, progress was a yardstick by which most men measured themselves against.

In terms of the first key question, there is hesitancy in our affirmative answer, due to the semantics of the word 'health,' and the issue of who determines whether meditation is a health behaviour - researchers or participants. It is doubtful whether many men would describe meditation in terms of health - most depicted it as a practice of spiritual development (although some defined such development in terms of becoming 'healthier' or overcoming illness). This depiction reflects the way meditation is often operationalized in academic research - i.e., a method for training psychological processes to increase wellbeing - with the consequence that meditation has generally been understood in the 'West' through psychological constructs like attention (Walsh \& Shapiro, 2006). Thus, it is perhaps more common for practitioners to regard meditation as a psychological tool than a health 
'behaviour.' That said, some men did describe living 'healthier' lives linked to their practice, and engaging in health behaviours such as abstinence (Author et al., XXXXb). For example, many felt meditation had increased their self-control, enabling them to resist the urge to drink, which indeed is the premise behind the use of meditation in therapies for the treatment of addiction (Witkiewitz et al., 2005).

However, regardless of how men themselves construed the function of their practice, we may construe their experiences of meditation as constituting a health behaviour. Even narrow conceptualisation of health like the medical model encompass mental health (Larson, 1999). As such, activities which reduce mental distress are health behaviours. Meditation was able to fulfil this function within limits, being considered a useful coping technique for managing some stress and distress. Here the narratives align with literature suggesting meditation can be helpful in treating mental disorders (Teasdale et al., 2000). Based on the World Health Organization and wellness models, which include mental wellbeing and even spiritual growth in their conceptualisations of health (Larson, 1999), men's accounts of meditation further qualify it as a health behaviour. Most narratives centred on the idea of progress in relation to psychological and/or spiritual growth, which is a key component of psychological wellbeing (Ryff, 1989). On this view, meditation may be deemed a 'wellbeingpromoting' behaviour. Finally, relationships men formed in communities around meditation indicate its potential to facilitate social dimensions of wellbeing. Indeed, the health benefits of religious communities, e.g., as a source of social support, have been acknowledged as part of the ‘religion-health connection’ (Ellison \& Levin, 1998).

Beyond simply identifying meditation as a health behaviour, we were interested in the ways men constructed their engagement with this apparently positive behaviour. In particular, we found that men above all experienced and understood their involvement with meditation through a prism of progress, often articulated specifically as 'spiritual progress.' The way in 
which this progress was conceptualised varied across individuals, with goals ranging from becoming happier to more 'integrated.' There are various ways of understanding the prominence of this idea. First, discourses around spiritual progress are recurrent motifs within Buddhist and other spiritual literature (Kumar, 2002). Then there is the intriguing possibility that these discourses may have intersected in complex ways with masculinity. Engaging with meditation appeared to enable men to rework the masculine self in unconventional ways. For example, spirituality is not regarded as traditionally masculine, partly since it conflicts with ideals around rationality (Ross-Smith \& Kornberger, 2004). However, just as Sloan et al. (2010) found in relation to exercise, this reworking still incorporated more conventional masculine ideals. In particular, as some participants themselves pointed out, the central theme of progress itself reflects a concern with linearity and achievement associated with conventional masculinity (Connell, 1995).

However, another interesting way of approaching the progress motif is through the concept of a 'health trajectory.' Strauss et al. (1984) articulated the concept of an 'illness trajectory' to depict how people experience illness in the context of their life. This concept is used to depict the progression of illness itself; for example, trajectories of prolonged gradual decline (e.g., dementia) versus steady progression with a clear terminal phase (e.g., cancer) (Murray, Kendall, Boyd, \& Sheikh, 2005). The concept is also used to refer to the personal transformation patients may undergo as a result of illness. Following the seminal work of Bury (1982), medical sociologists have highlighted the potential for illness to generate biographical disruption, affecting patients' self-identity, including the temporal narrative framing of their lives. Subsequently, patients are viewed as embarking on an illness 'career,' involving various types of 'work’ (Strauss, Fagerhaugh, Suczek, \& Wiener, 1982), including identity work. That is, in light of physical, psychological and social changes brought about through the illness experience, patients engage in an ongoing process of 'reconstructing' or 
'restoring' their self-identity (Charmaz, 1990). In the present study, engagement with healthy behaviours - in this case, meditation - can be similarly viewed as a 'health trajectory,' with implications for identity also, as elaborated further below.

Viewing men's accounts of their engagement with meditation as a 'health trajectory' is a useful way of understanding how men experience this engagement in the context of their lives. In particular, these accounts reveal how such trajectories can be undercut or challenged by various factors that impede men's sense of progress over time. These findings enhance our understanding of the way in which men may engage pro-actively with their health in general. More specifically, in terms of meditation, the findings challenge the burgeoning meditation literature which tends to discuss it in almost uniformly positive terms, with an 'absence of research' around difficulties associated with practicing (Irving, Dobkin, \& Park, 2009, p.65). Here, most men found maintaining a practice difficult, with progress problematic in various ways. Only two accounts - 'climbing' and 'springboard' - presented a picture of actual 'progress'; and even within these two accounts, there were complications, with the depiction of progress not unambiguously positive. For example, one man articulating a 'climbing' account had been unable to reconcile aspects of his practice (living in a Buddhist centre) with his relationship demands. Moreover, even within such accounts, the identity work undertaken by men could be challenging, even 'fearful,' as men navigated evolving identities, literally in some cases (e.g., taking on a new Buddhist name). The remaining four accounts revealed further the considerable challenges that destabilised men's construction of progress.

There were two principle challenges to men's sense of progress: conflict from other areas of life, and issues around illness and mortality. In terms of conflicts, men experienced pressures and other priorities, as evident in the 'bogged-down,' 'torn apart,' and 'stepping off' accounts. Here we might consider the idea of 'role-conflict,' defined as the 'simultaneous occurrence of two (or more) sets of pressures such that compliance with one would make 
more difficult compliance with the other’ (Kahn, Wolfe, Quinn, Snoek, \& Rosenthal, 1964, p.19). Role conflict has previously been used in studying health behaviours. Conceptualising exercise as a ‘leisure’ activity, Goff, Fick and Oppliger (1997) analysed how a commitment to running generated 'leisure-family' conflict. In this vein, there were multiple conflicts in the narratives in the present study, including 'leisure-work,' 'leisure-family,' and 'leisure-peer' conflicts, which collectively may be labelled 'leisure-life' conflicts. Such conflicts highlight the limitation of conceptualising the pursuit of wellbeing in an individualist way - as positive psychology is sometimes accused of doing (Becker \& Marecek, 2008) - without taking wider social contexts into account. Again, the complicated paths taken in these health trajectories also necessitated identity work. For example, in the 'stepping off' account, some men prevaricated over whether they self-identified as a meditator or not. These men generally claimed an identity as a meditator by fashioning a broader notion of what being a meditator consisted of, a notion that did not even depend on formally practicing meditation.

Of additional interest is how the various 'leisure-life' conflicts intersected with other factors, particularly socio-economics and gender, to further influence men's sense of progress. Regarding socioeconomics, men suggested that work-role conflict was heightened by the precarious economic climate, with progress being perceived by men as impeded by pressure to find/maintain employment. For some men, ‘leisure-work’ conflict was further exacerbated by 'leisure-family conflict' (Goff et al., 1997), creating a nexus of 'leisure-workfamily' conflict. Thus, while relationships are often seen as having a positive effect on health behaviours (Gallant, 2003), in our study they were sometimes perceived as a barrier to progress. Moreover, the 'leisure-work' conflict may have been exacerbated by gender factors, particularly the way traditional masculinity valorizes success and status (Courtenay, 2000b). Here, men strove for achievement in both domains, work and leisure, as epitomised by the drive towards ordination and progression within the Buddhist pathway. Masculinity may have 
also been a factor in the 'leisure-peer' conflict experienced by some men. For example, linked to the idea of spirituality not being 'masculine,' in the 'stepping off' account, men described being 'lured' away from meditation by peers, pressured to join in with ‘traditionally' masculine behaviours, like using alcohol (Courtenay, 2000b). The idea that social pressures can deter men from engaging in health practices is not new, but has hitherto not been identified in relation to meditation.

A second potent destabilising factor that troubled men's construction of progress was issues around illness and mortality. These issues reveal the complex intersection between illness trajectories and health trajectories. The 'torn apart' account included experiences of serious physical and/or mental illness curtailing men’s practice. As found in Bury’s (1982) work, these men experienced biographical disruption relating to their illness experience. This finding also problematizes the idea developed above of meditation being a progressive and healthy endeavour. Meditation often failed men during distressing times, e.g., exacerbating feelings of pain and low mood. This is in contrast to the way meditation is portrayed in the literature as an almost uniformly beneficial practice (Irving et al., 2009): although clinical adaptations using meditation for preventing depressive relapse acknowledge it as contraindicated for people currently suffering depression (Teasdale, Segal, \& Williams, 2003), there is little research on potential detrimental effects of meditation in non-clinical populations.

Finally, men's health trajectories were challenged in the 'reckoning' account by an awareness of mortality. There were tensions in these men's accounts between a health trajectory (the mind finding wisdom) and an illness trajectory (the body 'decaying'). This sense of existential finiteness is observed in the narratives of those with terminal cancer (Little, Jordens, Paul, Montgomery, \& Philipson, 1998). Just as such sufferers experienced their illness trajectories as bounded by the horizon of impending death, participants in the 
present study were coming to terms with their health trajectory having a 'visible' end point. However, even in this 'limit situation,' openness to the possibility of continued existence after death meant that these men had not completely foreclosed the possibility of their trajectory continuing, or even progressing, in some form. Perhaps the notion of being on a trajectory, and the idea of progressing to something, is so important to many men - and people in the West generally (Smith, 1999) - that not even death can completely dismantle it.

\section{Limitations and recommendations}

From the perspective of a 'hermeneutics of suspicion’ (Ricoeur, 1981), men’s narratives are not a simple recollection of facts, but a story told to an audience. However, while recognising a performative element to men's accounts, treating these just as performances does injustice to participants' efforts to 'speak the truth' about their lives (Connell, 1995, p.91). Thus, we can draw a number of key conclusions that may help encourage health behaviours in men.

First, given a range of conceptualisations of health in the literature, it is legitimate to view meditation as a health behaviour (even if its practitioners do not necessarily identify it as such): it is linked to behaviours that promote physical health, like alcohol moderation; it can help alleviate stress/distress (though not in all circumstances); and it can facilitate psychological and social wellbeing. However, the wider significance of this study lies in the way men experienced and constructed their engagement with such behaviour. We found that men's involvement with meditation could be viewed as a 'health trajectory,' with men constructing their engagement through a prism of progress. However, this trajectory could be undermined in manifold ways. Men experienced conflicts - with work, family, and peers that impeded their ability to maintain a practice. Some issues were further complicated by gender, with such conflicts exacerbated by masculinity norms, such as pressure for achievement in both work and 'leisure’ (i.e., meditation) domains. Health trajectories could also be undermined by illness trajectories, i.e., issues around illness and mortality. Although 
men's experiences in the present study pertained to meditation, future work could ascertain whether the concept of health trajectories applies to other health positive behaviours, and if so, how such trajectories are complexly constructed. Efforts to encourage men to engage in health behaviours could be informed by the notion of 'health trajectories'; this might include elucidating the potential for 'progress,' but also acknowledging its limitations, such as the potential for ‘cruel optimism’ (Berlant, 2011) in the face of impending mortality. 


\section{References}

Addis, M. E., \& Mahalik, J. R. (2003). Men, masculinity, and the contexts of help seeking. American Psychologist, 58(1), 5-14.

Becker, D., \& Marecek, J. (2008). Dreaming the American dream: Individualism and positive psychology. Social and Personality Psychology Compass, 2(5), 1767-1780.

Berlant, L. G. (2011). Cruel Optimism. Durham: Duke University Press.

Bury, M. R. (1982). Chronic illness as biographical disruption. Sociology of Health \& Illness, 4(2), 167-182.

Charmaz, K. (1990). 'Discovering'chronic illness: Using grounded theory. Social Science \& Medicine, 30(11), 1161-1172.

Connell, R. W. (1995). Masculinities. Berkeley, CA: University of California Press.

Conner, M., \& Norman, P. (1998). Health behaviour. In M. Johnston \& D. Johnston (Eds.), Health Psychology: Comprehensive Clinical Psychology (pp. 1-37). Oxford: Pergamon.

Courtenay, W. H. (2000a). Behavioral factors associated with disease, injury, and death among men: Evidence and implications for prevention. The Journal of Men's Studies, 9(1), 81-142.

Courtenay, W. H. (2000b). Constructions of masculinity and their influence on men's wellbeing: A theory of gender and health. Social Science \& Medicine, 50(10), 1385-1401.

Cutcliffe, J. R. (2005). Adapt or adopt: Developing and transgressing the methodological boundaries of grounded theory. Journal of Advanced Nursing, 51(4), 421-428.

Dalen, J., Smith, B. W., Shelley, B. M., Sloan, A. L., Leahigh, L., \& Begay, D. (2010). Pilot study: Mindful Eating and Living (MEAL): Weight, eating behavior, and psychological outcomes associated with a mindfulness-based intervention for people with obesity. Complementary Therapies in Medicine, 18(6), 260-264. 
Davidson, R. J., Kabat-Zinn, J., Schumacher, J., Rosenkranz, M., Muller, D., Santorelli, S. F., ... Sheridan, J. F. (2003). Alterations in brain and immune function produced by mindfulness meditation. Psychosomatic Medicine, 65(4), 564-570.

de Chavez, A. C., Backett-Milburn, K., Parry, O., \& Platt, S. (2005). Understanding and researching wellbeing: Its usage in different disciplines and potential for health research and health promotion. Health Education Journal, 64(1), 70-87.

de Visser, R. O., Smith, J. A., \& McDonnell, E. J. (2009). 'That’s not masculine’: Masculine capital and health-related behaviour. Journal of Health Psychology, 14(7), 1047-1058.

Denzin, N. K. (1978). The Research Act: A Theoretical Introduction to Sociological Methods. New York: Praeger.

Ellison, C. G., \& Levin, J. S. (1998). The religion-health connection: Evidence, theory, and future directions. Health Education \& Behavior, 25(6), 700-720.

Gallant, M. P. (2003). The influence of social support on chronic illness self-management: A review and directions for research. Health Education \& Behavior, 30(2), 170-195.

Goff, S. J., Fick, D. S., \& Oppliger, R. A. (1997). The moderating effect of spouse support on the relation between serious leisure and spouses' perceived leisure-family conflict. Journal of Leisure Research, 29(1), 47-60.

Gough, B. (2006). Try to be healthy, but don't forgo your masculinity: deconstructing men's health discourse in the media. Social science \& medicine (1982), 63(9), 2476-2488.

Irving, J. A., Dobkin, P. L., \& Park, J. (2009). Cultivating mindfulness in health care professionals: A review of empirical studies of mindfulness-based stress reduction (MBSR). Complementary Therapies in Clinical Practice, 15(2), 61-66.

Kahn, R. L., Wolfe, D. M., Quinn, R., Snoek, J. D., \& Rosenthal, R. A. (1964). Organizational Stress. New York: Wiley. 
Karasek, R. A. (1997). Demand/control model: A social,emotional, and physiological approach to stress risk and active behavior development. In J. M. Stellman (Ed.), ILO Encyclopedia of Occupational Health and Safety (pp. 34). Geneva: ILO.

Kumar, S. M. (2002). An introduction to Buddhism for the cognitive-behavioral therapist. Cognitive and Behavioral Practice, 9(1), 40-43

Larson, J. S. (1999). The conceptualization of health. Medical Care Research and Review, 56(2), 123-136.

Lee, W. K., \& Bang, H. J. (2010). The effects of mindfulness-based group intervention on the mental health of middle-aged Korean women in community. Stress and Health, 26(4), 341-348.

Little, M., Jordens, C. F. C., Paul, K., Montgomery, K., \& Philipson, B. (1998). Liminality: A major category of the experience of cancer illness. Social Science \& Medicine, 47(10), 1485-1494.

Mac an Ghaill, M., \& Haywood, C. (2012). Understanding boys’: Thinking through boys, masculinity and suicide. Social Science \& Medicine, 74(4), 482-489.

Mars, T. S., \& Abbey, H. (2010). Mindfulness meditation practise as a healthcare intervention: A systematic review. International Journal of Osteopathic Medicine, 13(2), 56-66.

Marshall, M. N. (1996). Sampling for qualitative research. Family Practice, 13(6), 522-526.

Murray, S. A., Kendall, M., Boyd, K., \& Sheikh, A. (2005). Illness trajectories and palliative care. BMJ: British Medical Journal, 330(7498), 1007-1011.

National Institute for Clinical Excellence (2004) Depression: Management of depression in primary and secondary care. clinical guideline 23. http://www.nice.org.uk/ CG023NICEguideline. 
Neilson, E. (1988). Health values: Achieving high level wellness - origins, philosophy, purpose. Health Values, 12, 3-5.

Noone, J. H., \& Stephens, C. (2008). Men, masculine identities, and health care utilisation. Sociology of Health and Illness, 30(5), 711-725.

Nutbeam, D. (1998). Health promotion glossary. Health Promotion International, 13(4), 349364.

Office for National Statistics (2012). Measuring National Well-being - Health.

Phillips, S. P. (2006). Risky business: Explaining the gender gap in longevity. The Journal of Men's Health and Gender, 3(1), 43-46.

Ricoeur, P. (1981). Hermeneutics and the Human Sciences (J. B. Thompson, Trans.). Cambridge: Cambridge University Press.

Ross-Smith, A., \& Kornberger, M. (2004). Gendered rationality? A genealogical exploration of the philosophical and sociological conceptions of rationality, masculinity and organization. Gender, Work \& Organization, 11(3), 280-305.

Ryff, C. D. (1989). Happiness is everything, or is it? Explorations on the meaning of psychological well-being. Journal of Personality and Social Psychology, 57(6), 10691081.

Savin-Baden, M., \& Niekerk, L. V. (2007). Narrative inquiry: Theory and practice. Journal of Geography in Higher Education, 31(3), 459-472.

Sloan, C., Gough, B., \& Conner, M. (2010). Healthy masculinities? How ostensibly healthy men talk about lifestyle, health and gender. Psychology \& Health, 25(7), 783-803.

Smith, B. (1999). "The Abyss: Exploring depression through the narrative of the self." Qualitative Inquiry 5(2): 264-279.

Smith, B., \& Sparkes, A. C. (2005). Men, sport, spinal cord injury, and narratives of hope. Social Science \& Medicine, 61(5), 1095-1105. 
Strauss, A., \& Corbin, J. (1998). Basics of Qualitative Research: Techniques and Procedures for Developing Grounded Theory (2nd ed.). Thousand Oaks, CA Sage.

Strauss, A. L., Corbin, J., Fagerhaugh, S., Glaser, B., Maines, D., Suczek, B., \& Wiener, C. L. (1984). Chronic Illness and the Quality of Life (2nd ed.). St. Louis: C. V. Mosby.

Strauss, A. L., Fagerhaugh, S., Suczek, B., \& Wiener, C. (1982). The work of hospitalized patients. Social Science \& Medicine, 16(9), 977-986.

Teasdale, J. D., Segal, S. V., \& Williams, J. M. G. (2003). Mindfulness training and problem formulation. Clinical Psychology: Science and Practice, 10(2), 157-160.

Teasdale, J. D., Segal, Z. V., Williams, J. M. G., Ridgeway, V. A., Soulsby, J. M., \& Lau, M. A. (2000). Prevention of relapse/recurrence in major depression by mindfulness-based cognitive therapy. Journal of Consulting and Clinical Psychology, 68(4), 615-623.

Ulmer, C. S., Stetson, B. A., \& Salmon, P. G. (2010). Mindfulness and acceptance are associated with exercise maintenance in YMCA exercisers. Behaviour Research and Therapy, 48(8), 805-809.

Walsh, R., \& Shapiro, S. L. (2006). The meeting of meditative disciplines and western psychology: A mutually enriching dialogue. American Psychologist, 61(3), 227-239.

Williams, A. L., Dixon, J., McCorkle, R., \& Van Ness, P. H. (2011). Determinants of meditation practice inventory: development, content validation, and initial psychometric testing. Alternative Therapies in Health and Medicine, 17(5), 16-23.

Witkiewitz, K., Marlatt, G. A., \& Walker, D. (2005). Mindfulness-based relapse prevention for alcohol and substance use disorders. Journal of Cognitive Psychotherapy, 19(3), 211-228.

World Health Organization (1948). Preamble to the Constitution of the World Health Organization as Adopted by the International Health Conference, New York, 19-22 June, 1946. 
Table 1. Sociodemographic Characteristics of the Sample of 30 Male Meditators

\begin{tabular}{cccccc} 
Age & & & & \\
\hline Years & $20-30$ & $30-40$ & $40-50$ & $50-60$ & $60+$ \\
Participants & $\mathrm{n}=4$ & 7 & 14 & 4 & 1 \\
\hline
\end{tabular}

Meditation experience

\begin{tabular}{cccccc}
\hline No. of years & $0-5$ & $5-10$ & $10-15$ & $15-20$ & $20+$ \\
Participants & 7 & 8 & 7 & 4 & 4 \\
\hline
\end{tabular}

Occupation

\begin{tabular}{cccccc}
\hline Category & Health & Community & Business & Education & Other \\
Participants & 9 & 5 & 5 & 3 & 8 \\
\hline
\end{tabular}

Education

\begin{tabular}{cccccc}
\hline Level & Secondary & College & University & Post-grad & Professional \\
Participants & 2 & 2 & 8 & 6 & 12 \\
\hline
\end{tabular}

Ethnicity

\begin{tabular}{ccccc}
\hline Category & White British & Mixed British & White other & Asian \\
Participants & 21 & 1 & 6 & 2 \\
\hline
\end{tabular}

